\title{
Além dos números: significados de crescimento por pequenos empreendedores do setor de software
}

\author{
Beyond numbers: meanings of growth by small entrepreneurs in the software \\ industry
}

\author{
Hilka Pelizza Vier Machado Doutora em Engenharia de Produção. Universidade Cesumar (UniCesumar) - Brasil. \\ https://orcid.org/0000-0002-2554-0025 hilkavier@yaho0.com \\ Arthur Gualberto Bacelar da Cruz Urpia Doutor em Economia. Universidade Cesumar (UniCesumar) - Brasil e Universidade Estadual \\ https://orcid.org/0000-0002-5273-6373 \\ de Maringá (UEM). arthurbacellar@yahoo.com.br
}

\section{RESUMO}

Esta pesquisa tem como objetivo compreender significados de crescimento de empresas atribuídos por pequenos empreendedores do setor de software, a fim de compreender os sentidos do crescimento para os empreendedores e para seus negócios. O crescimento de empresas foi entendido como um processo e os empreendedores são os agentes desse processo. As intenções e motivações de crescimento estão relacionadas aos significados que os empreendedores atribuem ao crescimento (MORRIS et al., 2006). Metodologicamente, o estudo é exploratório e o crescimento de empresas foi analisado na perspectiva subjetiva do fenômeno. A partir de um estudo qualitativo com seis pequenos empreendedores de software, os dados foram coletados em entrevistas abertas e a análise de conteúdo foi aplicada complementada pelo software Iramuteq. De acordo com os resultados, seis classes de palavras foram identificadas como significados de crescimento: a) maximização de resultados e competitividade; b) identificação e exploração de oportunidades; c) dimensão social; d) qualidade de vida; e) resultados econômicos e resultados do mercado; f) integração de conhecimento e recursos externos e impacto na vida pessoal. A principal contribuição teórica foi mostrar a multidimensionalidade dos significados do crescimento de empresas, indo além da dimensão econômica, mesmo no setor de software que é dinâmico atualmente.

Palavras-chave: crescimento de empresas; empresas de software; pequenas empresas; Iramuteq.

This research aims to understand the meanings of growth of businesses as attributed by small software entrepreneurs. Business growth was understood as a process, and the entrepreneurs are the agents of this process. Growth intentions and motivations are related to the meanings that entrepreneurs give to business growth (MORRIS et al., 2006). Methodologically, the study is exploratory, and the growth of business was analyzed in the subjective perspective of the phenomenon. It was developed based on a qualitative study with six small entrepreneurs of the software sector. Data were collected in open interviews and content analysis was applied complemented by the Iramuteq software. According to results, six classes of words were identified as meanings of business growth: a) maximization of results and competitivity; b) identification and exploration of opportunities; c) social dimension; d) quality of life; e) economics results and market results; $f$ ) integration of knowledge and external resources and impact in personal life. The main theoretical contribution was to show the multidimension of meanings for business growth, going beyond the economic dimension, even in the software sector that is dynamic nowadays.

Keywords: business growth; software enterprise; small business; Iramuteq.

Recebido em 28/03/2021. Aprovado em 27/04/2021. Avaliado pelo sistema double blind peer review. Publicado conforme normas da ABNT. https://doi.org/10.22279/navus.2021.v11.p01-18.1566 


\section{INTRODUÇÃO}

O crescimento de pequenas empresas é um fenômeno complexo que vem sendo estudado há décadas (DI PETTA et al., 2018; PENROSE, 2006). Um dos aspectos associados à complexidade é a sua variabilidade e inconstância. $O$ crescimento varia entre empresas e não apresenta um padrão regular, nem mesmo em uma mesma empresa (ACHTENHAGEN; NALDI; MELIN, 2010; ACHTENHAGEN; BRUNNINGE; MELIN, 2017; DAVIDSSON; ACHTENHAGEN; NALDI, 2010; DOBBS; HAMILTON, 2007). Ele apresenta variações ao longo do tempo (DAVIDSSON; ACHTENHAGEN; NALDI, 2010; MCKELVIE; WIKLUND, 2010; VERSIANI et al., 2018).

Outro desafio para compreensão do crescimento diz respeito as suas determinantes (CIRILLO et al., 2020). Por exemplo, em nível macro, condições econômicas e políticas públicas podem influenciar o crescimento de empresas. Em nível intermediário, a gestão, por meio de suas estratégias e planos, exerce influência no crescimento. $E$, em nível micro, o crescimento pode ser influenciado pelo empreendedor (SAUKONNEN, 2017). Quanto a esse último, salienta-se que aspectos subjetivos são relevantes para compreensão de gestão e desempenho de pequenas empresas (LENZIARDI, 2017). Nesse sentido, decisões de crescer ou não crescer podem estar associadas ao contexto ou ao papel de agência dos empreendedores, as quais situam-se além de dimensões econômicas (WRIGHT; STIGLIANI, 2012).

Deste modo, o empreendedor pode influenciar o crescimento de empresas na medida em que ele é o agente do processo de crescimento (WIKLUND; PATZELT; SHEPHERD, 2009), por meio de escolhas pessoais, ambições, intenções e expectativas (ACHTENHAGEN; NALDI; MELIN, 2010; BULLANOVA; ISAKSEN; KOLVEREID, 2016; DAVIDSSON; ACHTENHAGEN; NALDI, 2010; DI PETTA et al., 2018; HERMANS et al., 2012; KIRKWOOD, 2016; VENUGOPAL, 2016). Como escolhas pessoais derivam de processos cognitivos, intenções e motivações de crescimento estão associadas a significados que empreendedores atribuem ao crescimento (MORRIS; MIYASAKI; WATTERS; COOMBES, 2006). Nesse aspecto, o crescimento pode conter um significado econômico (ORSER; HOGARTH-SCOTT; RIDING, 2000; PENROSE, 2006), abrangendo expansão na riqueza ou na renda (MCKELVIE; WILKLUND, 2010), expansão em vendas e em lucratividade (JANSSEN, 2009); como também um significado de diversificação e de transformação e acúmulo de recursos (PENROSE, 2006).

$O$ crescimento pode ainda ser influenciado pelo setor de atividades. O dinamismo do setor e barreiras de entrada são variáveis determinantes para o crescimento (DAVIDSSON; ACHTENHAGEN; NALDI, 2010). Um setor que apresenta um dinamismo atualmente é o de base tecnológica, que foi impulsionado pelo surgimento de empresas no Vale do Silício, as quais em poucos anos atingiram valores de mercado acima de um bilhão de dólares. Esse fenômeno tem estimulado a propagação de novos entrantes que almejam o mesmo ritmo de crescimento. Entre empresas de base tecnológica situam-se as de software. O crescimento dessas empresas é dependente, além de outros fatores, de intenções de crescimento por parte de empreendedores e as intenções, por sua vez dependem do que significa o crescimento para os empreendedores. Nesse sentido, considerando a importância de significados atribuídos por empreendedores ao crescimento, esta pesquisa foi delineada para responder à questão: como se configura o significado do crescimento para pequenos empreendedores que atuam no setor de software?

O objetivo desta pesquisa foi compreender significados de crescimento para pequenos empreendedores que atuam em um setor dinâmico, que é o setor de software, a fim de compreender os sentidos do crescimento para os empreendedores e para seus negócios. Trata-se de um estudo exploratório e qualitativo que focou o fenômeno do crescimento na perspectiva subjetiva de pequenos empreendedores que atuam no setor de software.

Este artigo apresenta, inicialmente, uma abordagem sucinta sobre significados de crescimento de pequenas empresas, focando significados de crescimento e, em seguida, apresenta os procedimentos metodológicos da pesquisa, seguidos dos resultados e de considerações finais.

\section{CRESCIMENTO DE PEQUENAS EMPRESAS}

O crescimento pode ser estudado em quatro enfoques: a) modelos biológicos de crescimento, focando um processo gradual, similar a evolução do ciclo de vida; b) crescimento como resultante de eficiência 
e planejamento de tomada de decisão; c) crescimento alimentado por aspectos psicológicos, relacionados a motivações internas e fatores internos, como socialização; d) estudos integrativos (ORSER; HOGARTH-SCOTT; RIDING, 2000). Nesta pesquisa, o crescimento será estudado na terceira perspectiva, focando aspectos subjetivos.

Como resultante de "um processo intencional iniciado pelo empreendedor ou como um processo não intencional que ocorre ao logo do tempo" (RENNEMO; WIDDING; BOGREN, 2017), o crescimento deriva de três processos de desenvolvimento: a) aumento em quantidades (produção, exportações, número de empregados ou vendas); b) mudanças internas por meio de decisões administrativas e de planejamento que conduzem a um aumento no tamanho da empresa e a uma melhoria na qualidade, em distintos processos de crescimento por aumento na quantidade e como um processo interno de desenvolvimento; $c$ ) resultado de um processo de fusão ou incorporação (PENROSE, 2006).

Enquanto fenômeno objetivo, o crescimento pode ser compreendido como variável dependente ou independente, focando o processo, mais do que o resultado. McKelvie e Wilklund (2010) sugerem que pesquisas sobre crescimento se concentrem mais em compreender como e porque as empresas crescem, mais do que quanto elas crescem, ou seja, uma visão de um processo de desenvolvimento resultante do acúmulo de capacidades (PENROSE, 2006). No entanto, a dinâmica do crescimento é difícil de ser explicada dada a dificuldade de analisar o crescimento quando ele está ocorrendo (MCKELVIE; WIKLUND, 2010). Por isso, a maioria dos estudos foca em elementos antecedentes ou consequentes (LEITCH; HILL; NEERGAARD, 2010).

Quanto aos elementos consequentes, as formas de mensuração do crescimento são diversas. Expansão no volume de vendas ou no número de empregados são as principais formas de mensuração, sendo aplicadas em separado ou em conjunto (ACHTENHAGEN; NALDI; MELIN, 2010). Outras abordagens consideram o aumento de equipamentos e tecnologia (CHANDLER; MCKELVIE; DAVIDSSON, 2009), expansão na oferta de produtos (ACHTENHAGEN; NALDI; MELIN, 2010), melhorias na eficiência dos processos (DAVIDSSON; ACHTENHAGEN; NALDI, 2010) e diversificação e acúmulo de recursos (PENROSE, 2006).

Quanto ao ritmo de crescimento, empresas podem apresentar rápido crescimento, como as gazelas (PARKER; STOREY; WITTELOOSTUIJN, 2010). Para Saukkonen (2017), o ritmo pode apresentar três modalidades: crescimento, hiper crescimento e não crescimento. Além disso, o crescimento pode ser compreendido pela forma, como orgânico ou por aquisição (PENROSE, 2006). O crescimento orgânico pode apresentar trajetórias constantes e irregulares ao longo de um período (COAD et al., 2013).

Quanto a antecedentes, estudos procuram explicar determinantes de crescimento associadas a níveis macro, intermediário e individual. Em nível macro, sucintamente, o crescimento pode ser determinado, entre outros, pelos seguintes fatores: a) oscilações na oferta e demanda de produtos (COAD; TAMVADA, 2012; WRIGHT; STIGLIANI, 2012); b) dinamismo no setor e barreiras a novos entrantes (WRIGHT; STIGLIANI, 2012); c) presença de investidores e de capital de risco (DAVIDSSON; ACHTENHAGEN; NALDI, 2010); d) presença de universidades e de mecanismos de transferência de tecnologia (HERMANS et al., 2012); e) presença de networks ou redes de empresas (BARRINGER; JONES; NEUBAUM, 2005); f) políticas e programas de suporte às empresas (SCHOONJANS; CAUWENBERGE; BAUWHEDE, 2013).

Em nível intermediário, o crescimento da empresa pode ser influenciado, entre outros, pelos seguintes aspectos: a) aprendizado organizacional; b) inovação e desenvolvimento de produtos (ACHTENHAGEN; NALDI; MELIN, 2010; DAVIDSSON; ACHTENHAGEN; NALDI, 2010); c) desenvolvimento de competências gerenciais (PENROSE, 2006); d) estratégias de recursos humanos e mercadológicas (BARRINGER; JONES; NEUBAUM, 2005); e) exportação e internacionalização (ACHTENHAGEN; NALDI; MELIN, 2010; COAD; TAMVADA, 2012).

Em nível individual, entre fatores que influenciam o crescimento, constam o nível educacional e a experiência no setor de atuação (BARRINGER; JONES; NEUBAUM, 2005; DAVIDSSON; ACHTENHAGEN; NALDI, 2010), bem como aspirações de crescimento (HERMANS et al., 2012; SAUKKONEN, 2017). Outros fatores, como por exemplo, motivações e intenções de crescimento influenciam o crescimento (DOUGLAS, 2013; WRIGHT; STIGLIANI, 2012), assim como o otimismo (NEILL, 2018). Como uma experiência subjetiva, os empreendedores interpretam e atribuem sentido a suas ações com base em suas experiências e vivências e em informações que 
eles dispõem (VERSIANI et al., 2018). Com isso, é a partir dos significados que o crescimento tem para empreendedores que eles traçam expectativas, intenções e estratégias de crescimento.

\subsection{Significados de crescimento}

Significado consiste na "possibilidade de um signo referir-se a seu objeto" (ABBAGNANO, 2007, p. 901). O crescimento pode apresentar uma multiplicidade de significados. Os mais comuns são sinônimo de aumento no número de produtos vendidos (ACHTENHAGEN; NALDI; MELIN, 2010; PENROSE, 2006) ou combinação do aumento de produtos vendidos com a lucratividade (ACHTENHAGEN; NALDI; MELIN, 2010; DAVIDSSON; ACHTENHAGEN; NALDI, 2010; DOBBS; HAMILTON, 2007). O segundo significado mais frequente é o aumento no número de empregados (ACHTENHAGEN; NALDI; MELIN, 2010; DOBBS; HAMILTON, 2007; MITCHELMORE; ROWLEY, 2013). Rauch e Rijskijk (2013) consideram que este representa o modo mais estável de mensurar o crescimento. Por sua vez, Morris et al. (2006) salientam que empreendedores orientados a elevado crescimento enfatizam simultaneamente o aumento em vendas e a contratação de empregados.

Outros significados do crescimento estão associados à melhoria de qualidade de processos internos (PENROSE, 2006). De acordo com Leitch, Hill e Neergaard (2010), como o crescimento é sustentável ou consistente ao longo do tempo, ele resulta de um processo de desenvolvimento dos meios disponíveis. Este pode ser observado em diversas dimensões, tais como o desenvolvimento de competências, práticas organizacionais e de conhecimento (ACHTENHAGEN; NALDI; MELIN, 2010).

Além destes, o crescimento pode significar diversificação de produtos (DAVIDSSON; ACHTENHAGEN; NALDI, 2010; KIRKWOOD, 2009), aquisição de novas máquinas, equipamentos e aquisição de tecnologias (DOBBS; HAMILTON, 2007). Ele pode ser sinônimo da abertura de novas filiais (BRUSH; CERU; BLACKBURN, 2009; DAVIDSSON; ACHTENHAGEN; NALDI, 2010; PENROSE, 2006) ou abertura de outras empresas em diferentes setores de atividades no mesmo setor (PENROSE, 2006).

Como expansão de negócios, o crescimento pode significar aumento em exportações (PENROSE, 2006), o que está associado à expansão no mercado internacional. A ampliação de participação no mercado regional ou nacional também pode indicar crescimento da empresa (DAVIDSSON; ACHTENHAGEN; NALDI, 2010; PENROSE, 2006). O crescimento pode decorrer da compra ou aquisição de outras empresas (DELMAR; WIKLUND, 2008; PENROSE, 2006). Davidsson, Achtenhagen e Naldi (2010) salientam que é possível um crescimento orgânico, subsequente à aquisição. Penrose (2006) menciona ainda o crescimento por fusão.

Para pequenas empresas de base tecnológica, o crescimento representa uma escolha estratégia, associada ao acúmulo de diferentes tipos de conhecimentos. No setor de software, empreendedores precisam de competências técnicas, mas precisam desenvolver outras competências associadas ao pensamento estratégico, à orientação dos consumidores de seus serviços, à gestão de projetos, entre outras competências gerenciais (SUDIRMAN et al., 2020). O acúmulo dessas competências está diretamente associado ao desenvolvimento de novos produtos e ao crescimento dessas empresas (DEGLIGIANNI; VOUDOURIS; LIOUKAS, 2015). O empreendedor é então um agente importante no processo de crescimento, influenciado por aspectos subjetivos como intenções, expectativas e significados de crescimento, aspectos ainda pouco explorados em estudos (MACHADO, 2018). Além disso, o empreendedor influencia a cultura organizacional, que, por sua vez, influencia o crescimento de empresas de software (CEGARRA-NAVARRO et al., 2019; YUN et al., 2020).

\section{PROCEDIMENTOS METODOLÓGICOS}

A pesquisa é um estudo qualitativo e exploratório, realizado junto a pequenos empreendedores do setor de software. A pesquisa qualitativa é recomendada para tipos de problemas como o desta pesquisa, que consistem em desvendar como se configura o significado do crescimento para pequenos empreendedores que atuam no setor de software.

Foram selecionados seis pequenos empreendedores que atuam em um arranjo produtivo de software. O critério para escolha das empresas foi o tempo de experiência no setor. Nesse sentido, foram buscadas empresas que apresentassem, no mínimo, cinco anos de atuação no setor, seguindo critério de 
Rauch e Rijskijk (2013), que comentaram a importância do conhecimento e da experiência de empreendedores. Dos seis participantes, dois atuam há dez anos no setor de software, três há dezessete anos e um deles há 30 anos.

Partindo da premissa que o crescimento pode apresentar variação nos significados entre empresas (ACHTENHAGEN; NALDI; MELIN., 2010; PENROSE, 2006; WIKLUND; PATZELT; SHEPHERD, 2010) e que esses significados podem ser influenciados pelo setor de atividades (DAVIDSSON; ACHTENHAGEN; NALDI., 2010), esta pesquisa busca responder à questão: como se configura o significado do crescimento para pequenos empreendedores que atuam no setor de software? Com isso, a coleta de dados primários ocorreu por meio de entrevistas abertas, do tipo narrativa, com base no tópico: Fale sobre o crescimento de sua empresa, explicando o que ele significa para você e para sua empresa. Salienta-se que a entrevista narrativa é uma forma não estruturada de entrevista, de profundidade, tendo como pressuposto subjacente que a perspectiva do entrevistado se revela melhor na própria linguagem espontânea sobre o fenômeno (BAUER; GASKELL, 2002). As entrevistas foram realizadas com os empreendedores que criaram e que gerenciam as empresas, após contato e assinatura do Termo de Livre Consentimento e Participação. Elas foram gravadas com o consentimento dos participantes e transcritas logo após a realização. Para validação dos conteúdos, a transcrição foi enviada aos participantes por e-mail.

A técnica de análise dos dados foi a análise de conteúdo. Segundo Bardin (2011), a análise de conteúdo ocorre em três fases principais, que são: pré-análise, exploração do material e tratamento dos resultados. Para facilitar a aplicação da técnica de análise de conteúdo foi utilizada a ferramenta de análise textual, o software IRaMuTeQ (Interface de $R$ pour les Analyses Multidimensionnelles de Textes et de Questionnaires). Segundo Salviati (2017), o IRaMuTeQ processa o texto de modo a possibilitar que possam ser identificadas classes de vocabulários, o que permite inferir quais ideias o corpus textual deseja transmitir. Dentre as análises textuais possibilitadas pelo IRaMuTeQ destacam-se as estatísticas textuais, a classificação hierárquica descendente (CHD), a análise fatorial por correspondência (AFC), a análise de similitude e a nuvem de palavras.

As estatísticas textuais executam estatísticas simples sobre o 'corpus textual', que foi formado pelas transcrições das entrevistas realizadas, tais como identificação da quantidade de palavras, frequência e hápax (que são as palavras que aparecem uma única vez), pesquisa no vocabulário e redução das palavras com base em suas raízes e identificação das formas ativas e suplementares (SALVIATI, 2017).

Com a CHD, o IRaMuTeQ procura obter classes formadas por palavras que são significantemente associadas com aquela classe, ou seja, palavras com qui-quadrado $\left(x^{\wedge} 2\right)$ maior que 3,8 e $p<0,05$. O teste quiquadrado serve para avaliar quantitativamente a relação entre o resultado de um experimento e a distribuição esperada para o fenômeno. Ou seja, ele representa com quanta certeza os valores observados podem ser aceitos como regidos pela teoria em questão (SALVIATI, 2017). O valor-p é definido como a probabilidade de se observar um valor da estatística de teste maior ou igual ao encontrado. Tradicionalmente, o valor de corte para rejeitar a hipótese nula é de 0,05 , o que significa que, quando não há nenhuma diferença, um valor tão extremo para a estatística de teste é esperado em menos de 5\% das vezes" (FERREIRA; PATINO, 2015, p. 485). O CHD apresenta um esquema hierárquico de classes, tornando possível inferir quais ideias o corpus textual deseja transmitir (SALVIATI, 2017). Por sua vez, a AFC permite que sejam verificadas as relações entre as classes em um plano cartesiano, demonstrando a localização dessas classes e sua interação (NASCIMENTO; MENANDRO, 2006).

A análise de similitude se baseia na teoria dos grafos e possibilita a identificação das ocorrências entre as palavras, trazendo indicações da conexidade entre elas, e auxilia na identificação da estrutura de um corpus textual. Por fim, a nuvem de palavras, que é uma análise lexical mais simples, contribui para a análise textual por possibilitar a rápida identificação das palavras-chave de um corpus de texto (CAMARGO; JUSTO, 2013).

\section{APRESENTAÇÃO E ANÁLISE DOS RESULTADOS}

O corpus textual analisado foi composto por seis textos, representados pelas entrevistas realizadas, separados em 201 segmentos de textos (ST), dos quais 163 foram classificados pelo IRaMuTeQ, resultando em 
um aproveitamento de 81,09\%. Emergiram 3.891 ocorrências (palavras, formas ou vocábulos), com 733 lemas, 619 formas ativas, 106 formas suplementares e 601 palavras com uma única ocorrência (intitulado hapax).

O conteúdo analisado foi categorizado em 6 classes: classe 1, com 32 ST (19\%); classe 2, com 24 ST (14\%); classe 3, com 28 ST (17\%); classe 4, com 25 ST (15\%); classe 5, com 32 ST (19\%), e; classe 6, com 22 ST (13\%), conforme Figura 1.

Figura 1 - Dendograma das classes

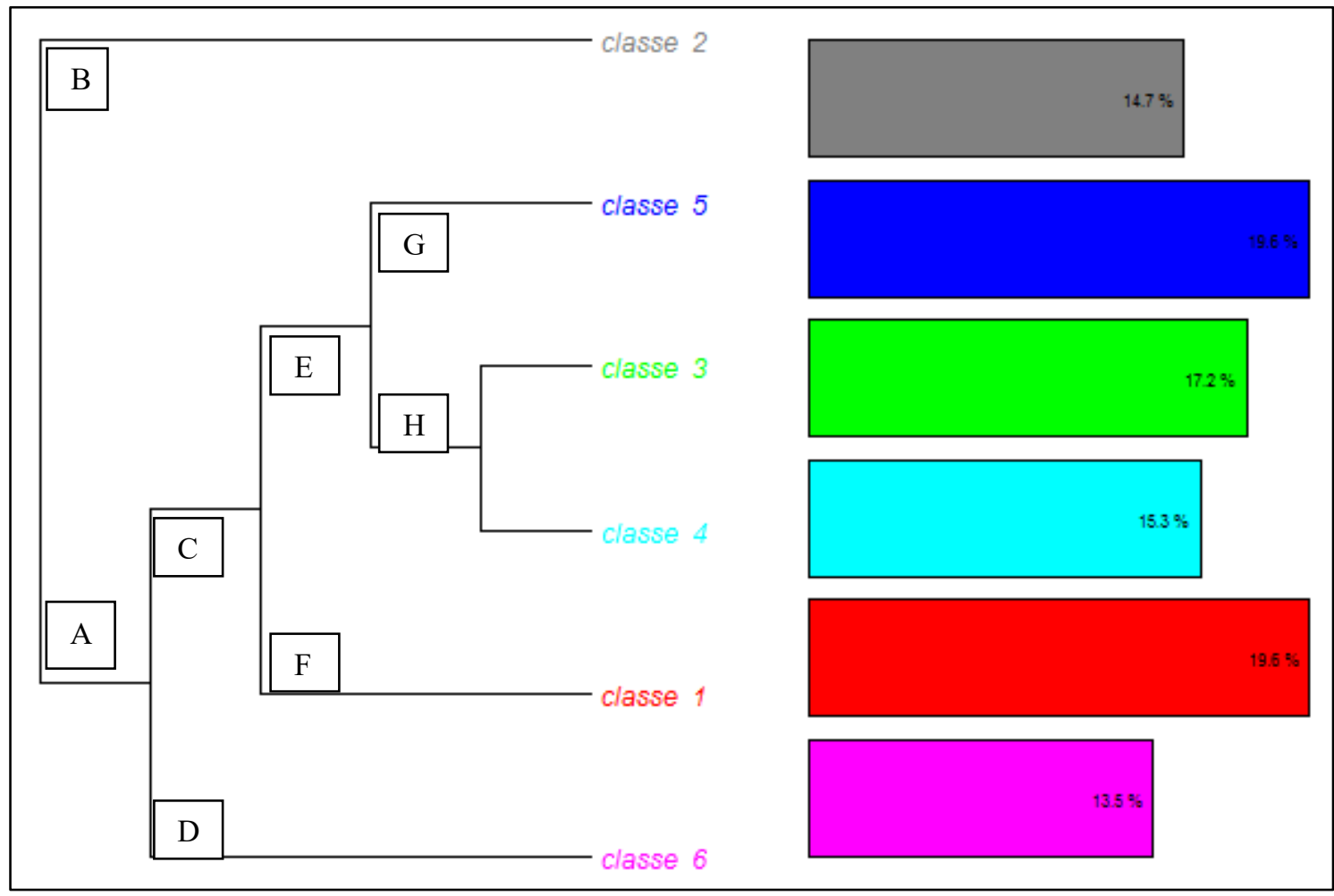

Fonte: Elaboração própria (2021).

Na Figura 1, observa-se que as 6 classes geradas se encontram, inicialmente, em 2 subcorpus. $O$ Subcorpus $A$ é composto pela classe 2 . O subcorpus $B$ conta com 2 ramificações $(C$ e $D)$. $A$ ramificação $D$ é composta pela classe 6 . Já a ramificação $C$ apresenta outras duas subdivisões ( $E$ e F), com a subdivisão $F$ sendo composta pela classe 1 e a subdivisão $E$ sendo composta pelos subgrupos $G$, que inclui a classe 5 , e $H$, que abrange as classes 3 e 4 . A Figura 2 apresenta as palavras pertencentes a cada classe e as relações entre as classes. 
Figura 2 - Filograma sobre as representações das Classes

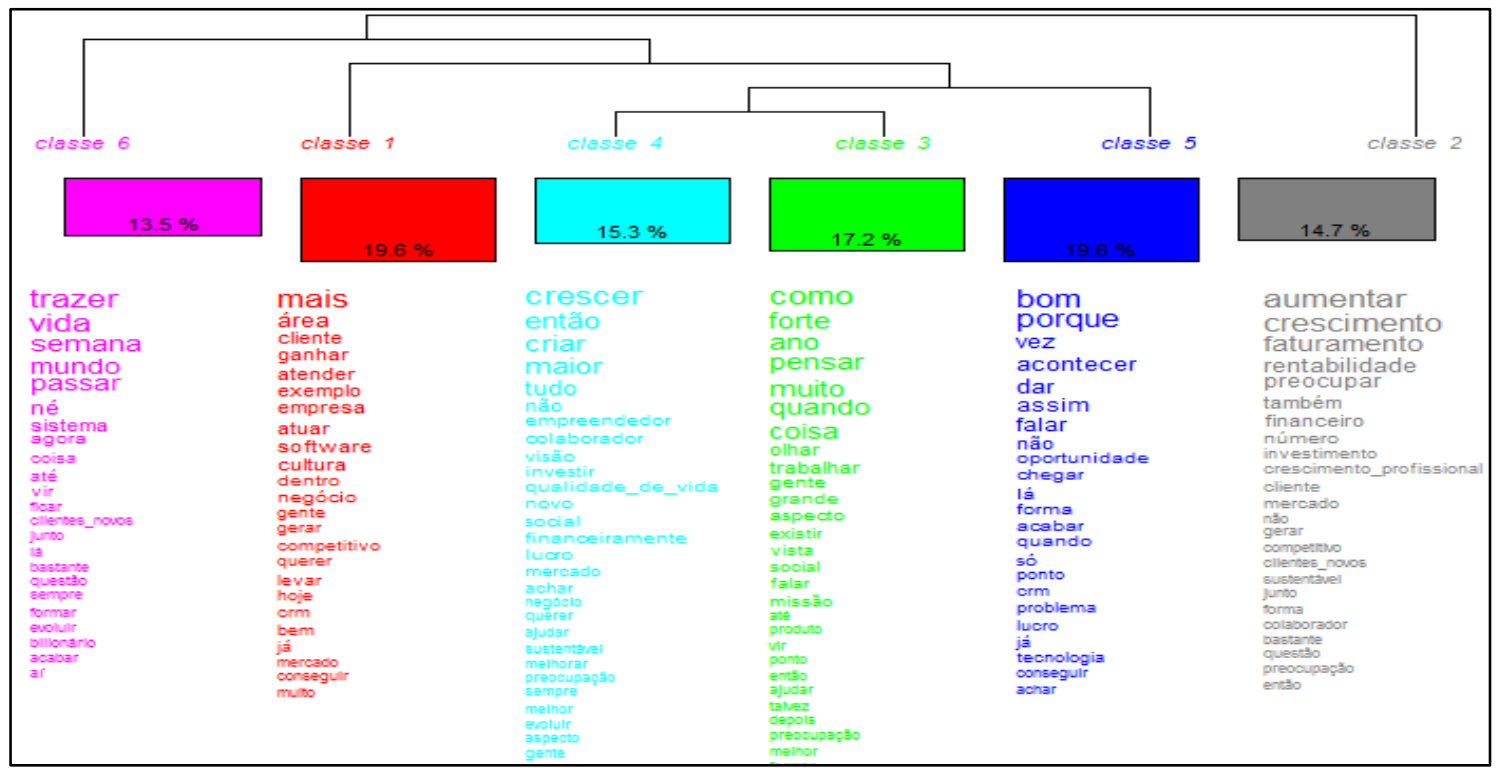

Fonte: Elaboração própria (2021).

A classe 2, categorizada de 'resultado econômico e mercado', compreende $14,7 \%$ do total do corpus analisado e é composta por palavras e radicais com intervalo qui-quadrado entre X2 $=5,42$ (ver) e X2 $=61,7$ (aumentar). As seguintes palavras se destacam: aumentar $(X 2=61,7)$, crescimento $(X 2=53,99)$, faturamento $(X 2=42,36)$, rentabilidade $(X 2=36,08)$, preocupar $(X 2=23,75)$, financeiro $(X 2=17,5)$, investimento $(X 2=6,57)$, crescimento profissional $(X 2=6,57)$, cliente $(X 2=4,56)$ e mercado $(X 2=3,86)$. Esta classe demonstra a preocupação das empresas em obter um resultado econômico sustentável para ampliar a participação do mercado, tal como pode ser observado nos seguintes fragmentos das entrevistas:

Crescer para nós é um conjunto que nós levamos em consideração, que é aumentar o faturamento, aumentar a rentabilidade de forma sustentável. Nos preocupamos com o crescimento do faturamento, com o crescimento da participação do mercado e com o crescimento da rentabilidade do negócio, pois não adianta somente aumentar o faturamento e ter prejuízo. Aumentar somente a rentabilidade também é possível, sem crescimento de ocupação do mercado... Se a gente só cuidar de aumentar a rentabilidade, sem se preocupar com expansão do mercado, a gente pode perder o mercado. Precisamos nos preocupar com as duas coisas, que são: em gerar valor para o cliente e gerar participação do mercado, valor interno dentro da empresa, diminuindo custo e sendo mais competitivo (Entrevistado 1).

O desafio do empreendedor, pelo menos na minha visão, é que não basta você criar uma empresa só para dizer tenho uma empresa, virei empresário. O empreendedor quer fazer isso ter continuidade. Ele quer colocar mais pessoas possíveis, na verdade ele quer criar negócios sustentáveis no longo prazo. (Entrevistado 4).

Obviamente, que você está falando de uma empresa, tem que ser rentável, se não é mais viável você vai partir para outro negócio, mas hoje não é um modelo de mercado visceral: crescer a qualquer custo, você ganhar posicionamento, ganhar projeção de marca. (Entrevistado 6).

A classe 6, categorizada de "integração de conhecimentos e recursos externos e impacto na vida pessoal", compreende $13,5 \%$ do total do corpus analisado e é composta por palavras e radicais com intervalo qui-quadrado entre $X 2=4,15$ (minha) e X2 $=40,36$ (trazer). Nesta classe destacam-se as palavras: trazer $(X 2=$ $40,36)$, vida $(X 2=39,92)$, semana $(X 2=33,06)$, mundo $(X 2=29,13)$, passar $(X 2=26,28)$, sistema $(X 2=15,08)$ e agora $(X 2=7,4)$. Com isto, verifica-se que a classe apresenta a busca por parte das empresas por conhecimentos e recursos externos na medida em que isto impacta na obtenção de novos clientes e na vida 
pessoal deles. Os seguintes excertos de entrevistas ilustram a integração de novos conhecimentos e recursos externos:

\begin{abstract}
Essa semana estamos vendo com o $D$, que é um órgão aqui, para trazer $M$, para trazer e ficar uma semana aqui para fazer uma reciclagem com a turma e mostrar as novidades [...] vamos trazê-lo pelo $D$ aí mais empresas aqui em $C$ possam usufruir disso, que a gente não é concorrente, somos amigos, então dá para fazer algo que fica bom financeiramente para todo mundo, porque ele não é um profissional barato........É uma forma simbólica, engraçada de falar, mas acho que todas as pessoas deveriam aproveitar essa oportunidade, essa dádiva que é a vida né, de fazer alguma coisa pelo ser humano, pela vida, para essa espécie que existe aqui, porque existem várias espécies, mas esta aqui precisa evoluir (Entrevistado 3).
\end{abstract}

Eu sempre digo para todo mundo assim, eu vou ser bilionário, mas eu nunca desejei isso na minha vida. E é fato, não me move querer mais dinheiro. Não me move. Eu acho que o que a gente fez aqui eu poderia vender e passar o resto da minha vida viajando, porque o que não falta é empresa querendo comprar, podia vender, pegar uns milhões, pôr no meu bolso, mas não é isso que me move, eu tenho projetos sociais na minha cabeça, ajudar crianças, famílias carentes, é já faço isso de alguma forma, não só no Brasil, fora do Brasil (Entrevistado 5).

A classe 1, categorizada de "maximização de Resultados e competividade", compreende 19,6\% do total do corpus analisado e é composta por palavras e radicais com intervalo qui-quadrado entre X2 =3,99 (querer) e X2 =47,29 (mais). Nesta classe destacam-se as seguintes palavras: mais $(X 2=47,29)$, área $(X 2=24,56)$, cliente $(X 2=17,06)$, ganhar $(X 2=16,79)$, atender $(X 2=16,79)$, empresa $(X 2=15,86)$, atuar $(X 2=12,51)$, software $(X 2=12,51)$, negócio $(X 2=9,11)$ e competitivo $(X 2=4,29)$. Na análise observa-se que estão elencadas palavras que se relacionam diretamente com a busca de maximização de resultados pelas empresas (o que compreende a necessidade de melhorar uma série de aspectos, incluindo o resultado financeiro) e por competitividade, como pode ser ilustrado com os trechos seguintes:

[...] a empresa crescendo ela vai ter mais dinheiro e ela consegue fazer outros investimentos então a gente tem hoje empresa que atua na área médica, empresa que faz BPO (business outsourcing, quando a gente assume uma parte da operação), empresas telefônicas, empresas para a área jurídica. A empresa expandindo ela consegue abrir novos negócios e eu consigo trazer para algum lugar, algum ponto, novas oportunidades de trabalho, de negócios que se a empresa não cresce essa oportunidade não vai ser criada (Entrevistado 2).

Precisamos nos preocupar com as duas coisas, que são: em gerar valor para o cliente e ampliar a participação do mercado, valor interno dentro da empresa, diminuindo custo e sendo mais competitivo (Entrevistado 1).

A classe 5, categorizada de "identificar e explorar oportunidades", compreende 19,6\% do total do corpus analisado e é composta por palavras e radicais com intervalo qui-quadrado entre X2 =3,99 (quando) e $X 2=21,12$ (bom). Nesta classe destacam-se as seguintes palavras: bom $(X 2=21,12)$, acontecer $(X 2=11,91)$, $\operatorname{dar}(X 2=11)$, oportunidade $(X 2=5,33)$, chegar $(X 2=5,33)$, forma $(X 2=4,29)$ e acabar $(X 2=4,29)$. Esta classe demonstra a busca por oportunidades de mercado, evidenciando a dinamicidade do setor:

[...] mas uma oportunidade que aparece talvez você não esteja tão pronto para aquela oportunidade, mas você abraça. Já aconteceram alguns casos assim, então precisa ter coragem para às vezes assumir um compromisso, faz alguma diferença e se você olhar a oportunidade e olhar o que você tem em casa e você fala assim não dá, mas se eu arriscar de repente eu consigo negociar alguma coisa e pode ser que a gente consiga e algumas vezes a gente tentou ....eu começo a enxergar oportunidades, por exemplo, a gente tem um negócio que a gente investiu há algum tempo na área hospitalar, software para a área hospitalar, eu tenho aqui 20 pessoas que eu não teria se a gente não tivesse investido nisso (Entrevistado 2).

Por exemplo, começamos no mercado diferencial e fomos aí pelo quarto ano da empresa a que mais tinha (e na época se baixava muito os softwares pelos super downloads) downloads em sistemas de CRM, a gente ganhou muito mercado da própria Microsoft, pois 
era muito complexo o CRM deles. O CRM deles não falava, era aquela metodologia que foi desenvolvida nas universidades, e a gente conhece que nas empresas brasileiras você tem uma cultura de ser um pouco mais flexível quanto a isso (Entrevistado 6).

A classe 3, denominada "dimensão social", compreende $17,2 \%$ do total do corpus analisado e é composta por palavras e radicais com intervalo qui-quadrado entre $\mathrm{X} 2=5,26$ (aspecto) e X2 $=24,15$ (como). Nesta classe destacam-se as palavras: como $(X 2=24,15)$, forte $(X 2=19,77)$, ano $(X 2=19,54)$, pensar $(X 2=$ $19,16)$, muito $(X 2=19)$, quando $(X 2=15,42)$, olhar $(X 2=8,21)$, trabalhar $(X 2=8,21)$, gente $(X 2=5,63)$, grande $(X 2=5,26)$ e aspecto $(X 2=5,26)$. Nota-se que nesta classe estão elencadas palavras que se relacionam com aspectos sociais vivenciados pelos empreendedores, como pode ser observado nos seguintes fragmentos das entrevistas:

Então esse trabalho que eu vejo que recebi tipo uma missão. Estou fazendo pessoas mais felizes, buscando objetivos, crescendo, porque vejo assim se você vier para a terra e morrer sem fazer nada, você não deixa um legado. Eu acho que eu contribuo, como um jogo de futebol, você é o goleiro, você é o técnico, você é o atacante, cada um é escalonado para uma função, eu fui escalonado para essa função e tenho que fazer isso então muitas vezes (Entrevistado 3).

Como empreendedor, acho que o objetivo de crescer é criar negócios sustentáveis, negócios que fazem história, que tenham realmente uma missão e essa missão é mais do que receber dinheiro, mas, sim, levar valores para sociedade (Entrevistado 4).

A gente tem uma responsabilidade social muito forte, muito grande, aqui tem 200 pessoas, mas muitos são pais e filhos e nada nada a gente alcança 1000 pessoas que estão para ter seu desempenho particular, então tem esse aspecto social que a empresa faz realmente, tem pessoas que estão com a gente aqui desde 15 anos atrás. Então tem todo esse aspecto social que é quase direto (Entrevistado 2).

Então é isso que me move, essa causa maior, o que é que eu vou poder fazer com isso que a gente criou? Tem coisas que a gente já está fazendo para ajudar, que eu acho que eu posso contribuir, nós estamos lançando o clube de leitura e tecnologia, que é proibido falar de produto e de venda, é para ajudar o empresário a entender os desafios do negócio dele, vamos ler livros de administração juntos com o empresário, um livro de negócios, vamos falar de tecnologia, essa é a ideia, levar conteúdo para os empresários e ajudar de alguma forma, que eu possa até ser beneficiado com a minha marca, não tem problema, mas eu não vou vender nada, isso eu acho que faz a diferença, pode ajudar outras pessoas (Entrevistado $5)$.

A classe 4, que foi categorizada de 'qualidade de vida', corresponde a $15,34 \%$ do total do corpus analisado e é composta por palavras e radicais com intervalo qui-quadrado entre X2 =6,2 (cada) e X2=23,04 (crescer). Nesta classe destacam-se as palavras: $\operatorname{crescer}(X 2=23,04)$, maior $(X 2=16,61)$, criar $(X 2=16,61)$, colaborador $(X 2=6,2)$, empreendedor $(X 2=6,2)$, visão $(X 2=5,76)$ e trabalho $(X 2=7,92)$. Nota-se que nesta classe estão elencadas palavras que se relacionam com qualidade de vida, tal como pode ser observado nos seguintes fragmentos das entrevistas:

Olha nós definimos como missão da empresa promover a excelência em gestão empresarial, ou seja, fazer com que as outras empresas tenham melhor gestão, porque isso vai melhorar a qualidade de vida das pessoas, vai tornar nossa comunidade, as pessoas com quem a gente se relaciona mais competitivas, vai gerar mais qualidade de vida e mais poder econômico. A gente quer crescer para que as pessoas vivam melhor. Temos no nosso site princípios: o nosso cliente é nosso sucesso, ou seja, a gente quer que com nosso trabalho a gente possa fazer as empresas melhorarem. Então o crescimento, na verdade, é uma consequência; a gente aqui não tem uma preocupação vamos crescer e temos que crescer de qualquer jeito, nós temos que crescer acima de tudo com propósito de valores que nos fizeram chegar aonde estamos e proporcionando essa melhoria na qualidade de vida das pessoas (Entrevistado 1). 
Eu agrego a questão do trabalho com uma visão de vida. Então você me pergunta, por que você come, por que vai passear, por que você compra um carro, uma roupa bonita? É para o meu bem-estar (Entrevistado 3).

Em síntese, considerando as representações de classes de acordo com o percentual de palavras, a classe 1 (maximização de resultados e competitividade) e a classe 5 (identificar e explorar oportunidades) compreenderam o maior percentual do corpus analisado, ambas com 19,63\% cada uma. Isto demonstra que, no total do corpus do texto analisado, as discussões sobre maximização de resultados e competitividade tiveram um peso equivalente às discussões sobre identificar e explorar oportunidades por parte das empresas. A classe 3 (dimensão social) foi a que apresentou o segundo maior percentual do corpus do texto, com 17,2\%, o que demonstra o quanto as discussões sobre a dimensão social foram relevantes no total do corpus analisado. Já a classe 6 (integração de conhecimento e recursos externos e impacto na vida pessoal) foi a que apresentou o menor percentual do corpus do texto analisado, com apenas 13,5\%. O Quadro 1 apresenta uma síntese das dimensões contidas nos significados e o percentual de cada uma no corpus total.

Quadro 1- Síntese das Estatísticas textuais

\begin{tabular}{|c|c|c|c|}
\hline Dimensão & \% Corpus & Palavras & Interpretação do significado \\
\hline $\begin{array}{lr}\text { Maximização } & \text { de } \\
\text { Resultados } & \text { e } \\
\text { competitividade } & \end{array}$ & 19,6 & $\begin{array}{l}\text { Competitividade. } \\
\text { Negócio. } \\
\text { Mais. } \\
\text { Atuar. } \\
\end{array}$ & \begin{tabular}{lll}
\multicolumn{3}{l}{ Crescimento por meio de redução } \\
de custos para gerar \\
oportunidades, \\
investimentos.
\end{tabular} \\
\hline $\begin{array}{l}\text { Identificar e explorar } \\
\text { oportunidades }\end{array}$ & 19,6 & $\begin{array}{l}\text { Acontecer. } \\
\text { Oportunidade. } \\
\text { Forma. }\end{array}$ & $\begin{array}{l}\text { Crescimento como resultado de } \\
\text { aproveitamento } \\
\text { oportunidades. }\end{array}$ \\
\hline Social & 17,2 & $\begin{array}{l}\text { Olhar. } \\
\text { Trabalhar. } \\
\text { Gente. } \\
\text { Pensar. }\end{array}$ & \begin{tabular}{l}
\multicolumn{3}{l}{ Crescimento é acompanhado de } \\
missão social, \\
responsabilidade social e de \\
dever social.
\end{tabular} \\
\hline Qualidade de vida & 15,3 & $\begin{array}{l}\text { Crescer } \\
\text { Criar } \\
\text { Colaborador } \\
\text { Trabalho } \\
\end{array}$ & $\begin{array}{l}\text { Crescimento para qualidade de } \\
\text { vida do empreendedor e de } \\
\text { outras pessoas. }\end{array}$ \\
\hline $\begin{array}{l}\text { Resultado Econômico e } \\
\text { de Mercado }\end{array}$ & 14,7 & $\begin{array}{l}\text { Faturamento. } \\
\text { Rentabilidade. } \\
\text { Investimento. } \\
\text { Cliente. } \\
\text { Mercado. }\end{array}$ & $\begin{array}{l}\text { Rentabilidade e crescimento de } \\
\text { mercado para assegurar } \\
\text { sustentabilidade no longo prazo. }\end{array}$ \\
\hline $\begin{array}{lr}\text { Integração } & \text { de } \\
\text { conhecimentos e de } \\
\text { recursos externos e } \\
\text { impacto na vida pessoal. }\end{array}$ & $13,5 \%$ & $\begin{array}{l}\text { Vida. } \\
\text { Mundo. } \\
\text { Sistema. }\end{array}$ & $\begin{array}{l}\text { Crescimento tem uma dimensão } \\
\text { coletiva e sistêmica e afeta a vida } \\
\text { de clientes e de outras pessoas. }\end{array}$ \\
\hline
\end{tabular}

Elaboração própria com os dados da pesquisa (2021).

Na sequência, foi realizada a análise fatorial por correspondência (AFC) e identificou-se entre as palavras, considerando a frequência de incidência destas em classes, representando-as em um plano cartesiano. Na Figura 3, verifica-se que as classes 3, 5 e 6 encontram-se no quadrante 1 (representado por Q1 na figura), que se localiza na parte superior esquerda do plano cartesiano. Já a classe 4 se encontra centralizada no plano cartesiano. Tal representação já era esperada, a integração de conhecimentos e recursos externos e impacto na vida pessoal (classe 6) apresenta uma relação próxima com identificar e explorar oportunidades (classe 5), na medida em que a integração de conhecimentos e recursos externos viabiliza a identificação e exploração de oportunidades (BARON; SHANE, 2005). Por sua vez, a dimensão social (classe 3) apresentou dependência com as classes 5 e 6 . Por outro lado, a dimensão qualidade de vida (classe 4) apresenta relação direta com todas as classes, por isso ela se encontra centralizada no plano cartesiano. A classe 2 (resultado 
econômico e mercado) se encontra no quadrante 2, enquanto a classe 1 (maximização de resultados e competitividade) se encontra distribuída entre os quadrantes 3 e 4.

Figura 3 - Análise Fatorial por Correspondência

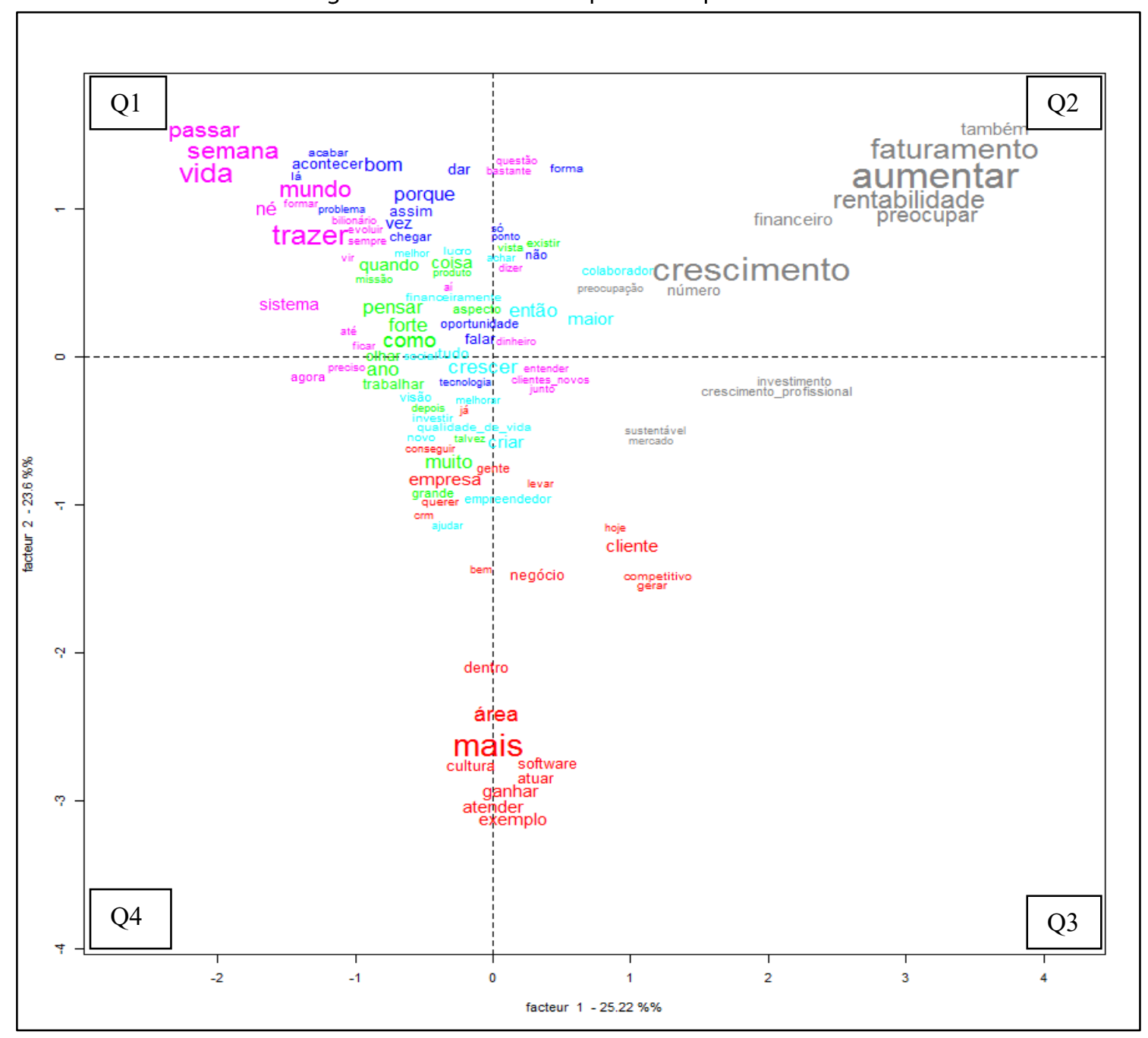

Legenda:

\section{Classe $6 \square$ Classe $5 \square$ Classe $4 \square$ Classe $3 \square$ Classe 2}

Elaboração própria (2021).

Na sequência, elaborou-se a nuvem de palavras e a análise de similitudes, mostradas nas Figuras 4 e 5. 
Figura 4 - Análise de Similitude

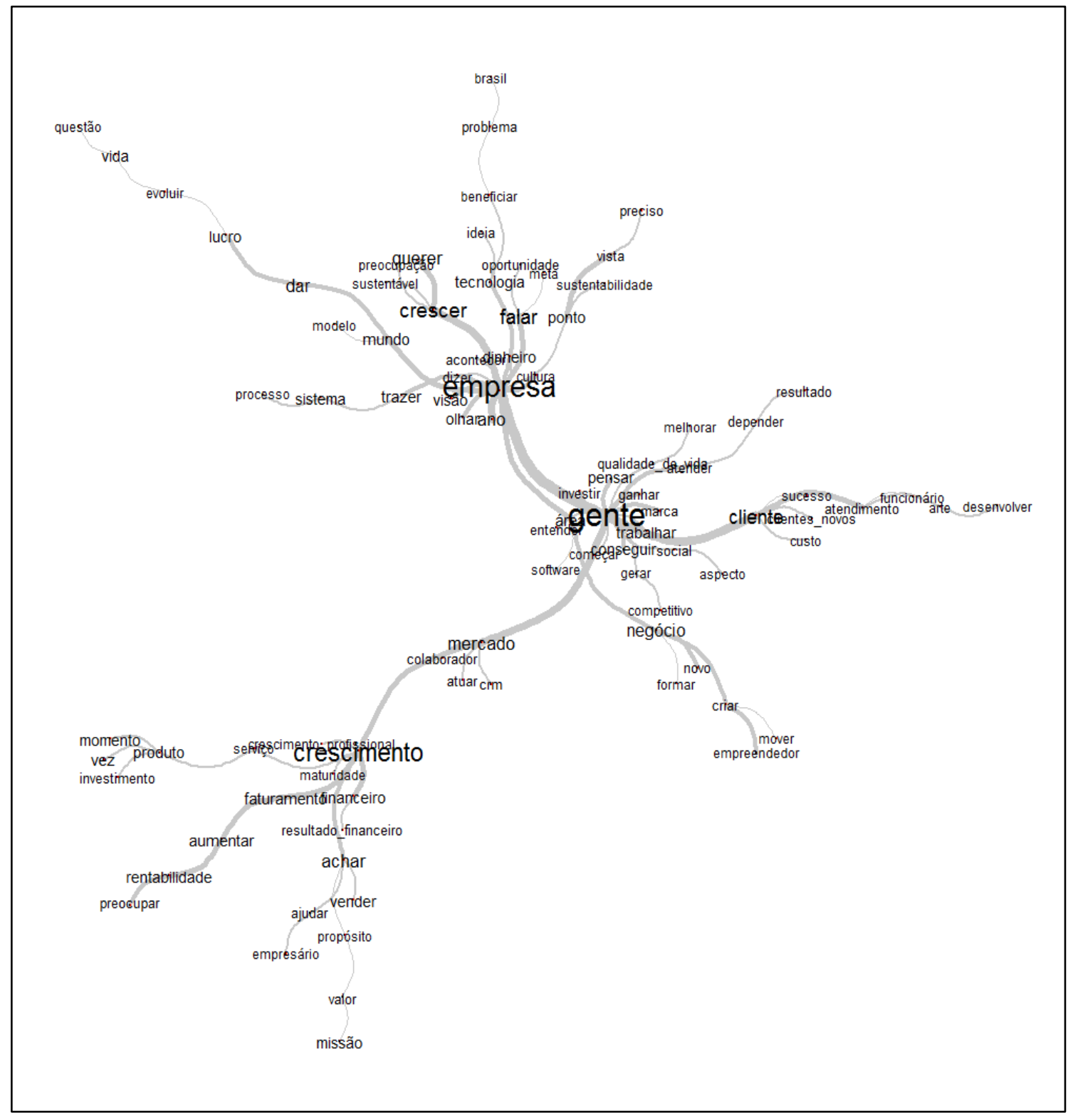

Fonte: Elaboração própria (2021).

Os resultados da análise de similitude mostrados na Figura 4, reforçam os resultados do Quadro 1. Nota-se a formação de três agrupamentos. Primeiramente, o agrupamento em torno da palavra gente, que representa a dimensão coletiva e social do crescimento, abrangendo expressões tais como social, cliente, funcionário, empreendedor, qualidade de vida. Outro agrupamento formado em torno da palavra crescimento, denotando a dimensão econômica, por meio de palavras como: investimento, produto, rentabilidade, aumentar, faturamento, resultado financeiro e vender. Um terceiro agrupamento foi formado em torno da palavra empresa, com os termos: oportunidade, tecnologia, sustentabilidade, modelo, sustentável, processo, sistema e cultura. As palavras empresa, gente e crescimento também aparecem no centro da nuvem de palavras, mostrada na Figura 5. 


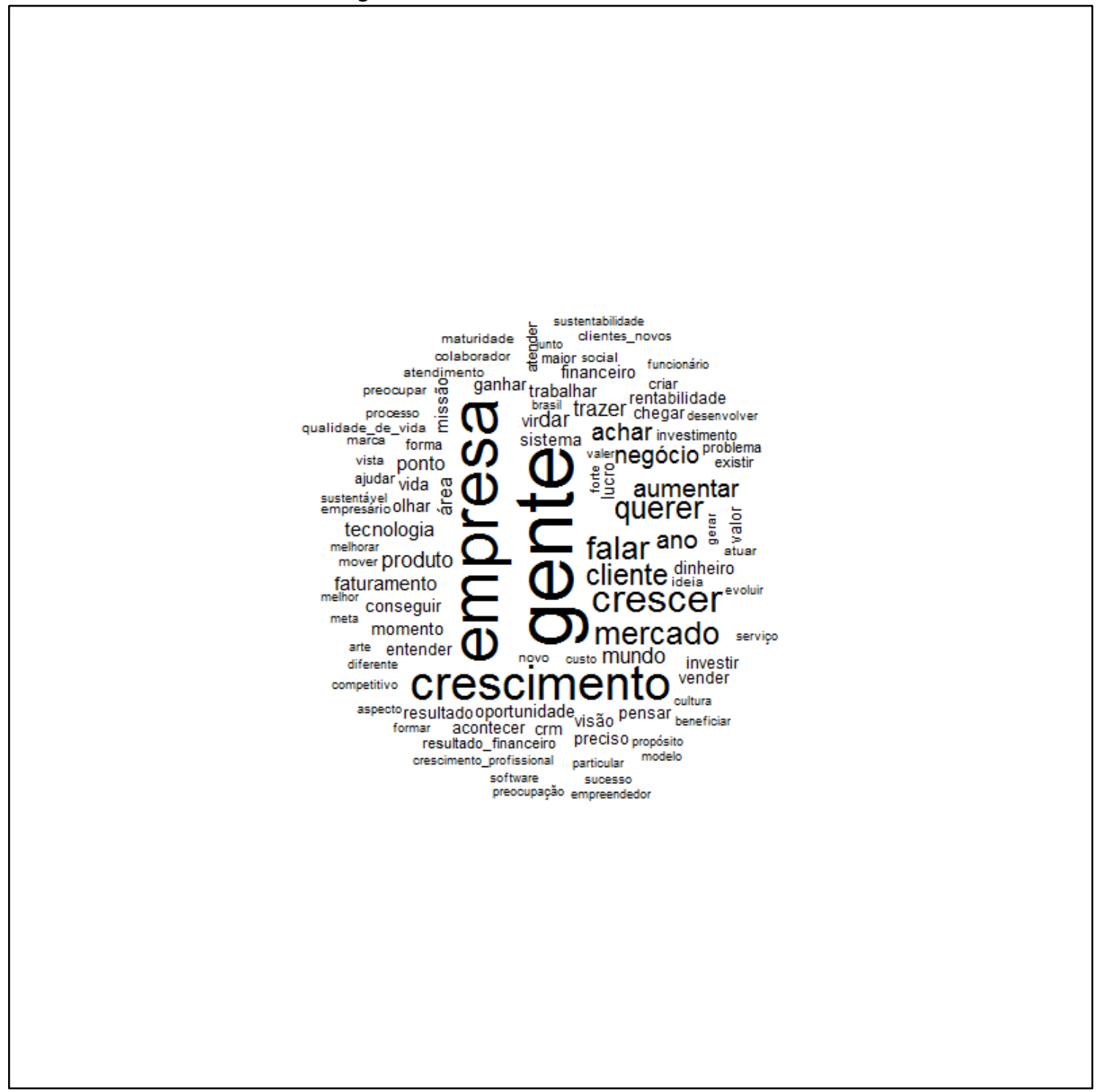

Fonte: Elaboração própria (2021).

\subsection{Significados de crescimento de empresas de software de acordo com os dados da pesquisa}

Os resultados da pesquisa apontam que os empreendedores desta pesquisa atribuem diferentes significados ao crescimento de suas empresas. Inicialmente, o crescimento se apresenta para eles como a busca de maximização de resultados e de competitividade, busca de mercado, bem como o resultado de um esforço orientado a identificar e explorar oportunidades (reunidos nas classes 2, 1 e 5). Nesse sentido, o crescimento apresenta um significado econômico, associado à busca de riqueza, corroborando com estudos anteriores (MCKELVIE; WIKLUND, 2010; ORSER; HOGARTH-SCOTT; RIDING, 2000).

Além da dimensão econômica, a dimensão social está presente nos significados de crescimento, por meio da missão e dever social mencionado pelos entrevistados. 0 crescimento para os empreendedores que participaram desta pesquisa vai além de resultados econômicos, abrangendo resultados sociais (CIRILLO et al., 2020). Com isso, o crescimento não representa para eles um fim em si mesmo. Mesmo em um setor que apresenta empresas de crescimento rápido, como o de software (PARKER; STOREY; WITTELOOSTUIJN, 2010), o sentido do crescimento para os empreendedores é o de um crescimento orgânico (PENROSE, 2006), com dimensões econômicas e sociais. 
Outra dimensão que apareceu no corpus do texto foi a qualidade de vida para o empreendedor e para outras pessoas (classes 3 e 4). Nesse sentido, esse resultado corrobora a afirmação de Yuksel, Sianne e Slade (2020), que o crescimento de empresas desafia a identidade dos empreendedores, os quais aspiram objetivos pessoais e autorrealização.

De modo geral, os resultados da pesquisa mostraram que significados de crescimento se revelam em discursos, os quais podem variar entre setores ou atividades (SAUKKONEN, 2017). Tal como Clarke, Holt e Blundel (2014) afirmam, o crescimento é um produto de ação coletiva e é multidimensional, como foi observado nos significados apresentados pelos empreendedores que participaram desta pesquisa.

Por outro lado, não foram identificadas nos significados de crescimento alguns pontos importantes para o crescimento de empresas de software e empresas em geral, como a exportação e a internacionalização (ACHTENHAGEN; NALDI; MELIN, 2010; ARROYO; FUENTES; JIMÉNEZ, 2016; COAD; TAMVADA, 2012). Pouca ênfase também foi dada aos termos criatividade, importante para crescimento de empresas de tecnologia (ANTONCIC; ANTONCIC; LI., 2018) e relação entre empresas e universidades, que demonstrou efeito positivo sobre crescimento de empresas tecnológicas (MIN et al., 2020). Em empresas de tecnologia há uma relação entre conhecimento e crescimento (DEGLIGIANNI; VOUDOURIS; LIOUKAS, 2015), e, embora não tenha aparecido com este termo no corpus do texto, na nuvem de palavras identifica-se a palavra tecnologia e na análise de similitude (Figura 4) encontram-se termos como processo, sistema e tecnologia, que estão associados a conhecimento. Além disso, entende-se que a classe 6, categorizada de "integração de conhecimentos e recursos externos e impacto na vida pessoal" está associada a capacidade absortiva da empresa, o que denota a importância atribuída indiretamente aos modos de busca de informações, conhecimento e tecnologia. Identifica-se ainda uma menção às redes n corpus do texto, onde constam parcerias com outras empresas.

\section{CONCLUSÃO}

Compreender significados de crescimento para pequenos empreendedores de software é importante, pois empreendedores são agentes do processo de crescimento (WIKLUND; PATZELT; SHEPHERD, 2009). Esta pesquisa apresentou significados que pequenos empreendedores de base tecnológica atribuem ao crescimento de suas empresas, evidenciando a importância de dimensões subjetivas na compreensão do crescimento.

A utilização do software Iramuteq contribuiu para uma análise léxica e quantitativa do corpus do texto. Com isso, seis classes de palavras foram identificadas como significados de crescimento, sendo: a) maximização de resultados e competitividade; b) identificação e exploração de oportunidades; c) social; d) qualidade de vida; e) resultado econômico e de mercado; f) integração de conhecimentos e de recursos externos e impacto na vida pessoal. Cabe destacar que empresas do setor de tecnologia apresentam um elevado crescimento e competitividade (SAUKKONEN, 2017), mas apesar disso há também uma dimensão social e coletiva do crescimento nos significados atribuídos pelos empreendedores.

Com isso, este estudo apresenta contribuições para o campo de estudos de pequenas empresas e para o campo da inovação, ao focar em empresas pequenas de software. Diferente de muitos estudos com esse segmento de empresas, esta pesquisa teve como análise as subjetividades, evidenciando a importância do mindset empreendedor sobre o crescimento de pequenas empresas de software.

Como contribuição prática, a pesquisa aponta elementos para a formulação de políticas voltadas e empresas desse segmento. Além disso, é importante considerar que empresas de software contribuem para o crescimento de outras empresas porque os serviços que elas prestam está diretamente associado com a melhoria da rentabilidade e melhoria de operações de outras empresas (CANO; BAENA, 2015). Entende-se ainda que ao compartilhar os sentidos de crescimento de empreendedores de pequenas empresas de software esta pesquisa pode despertar o interesse deles ou de empreendedores de outros setores sobre a amplitude possível de significados do crescimento de empreendimentos.

Uma das limitações deste estudo foi incluir apenas empreendedores com experiência superior a cinco anos, na medida em que empreendedores iniciantes podem apresentar diferentes significados do 
crescimento. Outra limitação foi não incluir grandes empresas de software, as quais podem apresentar outras dimensões, como, por exemplo, a internacionalização, não encontrada neste estudo. Com isso, para estudos futuros, sugere-se ampliar a compreensão de significados de crescimento de empreendedores de grandes empresas de software, como também junto a empreendedores iniciantes.

\section{REFERÊNCIAS}

ABBAGNANO, N. Dicionário de Filosofia. São Paulo: Martins Fontes, 2007.

ACHTENHAGEN, L.; NALDI, L.; MELIN, L. Business growth - Do practitioners and scholars really talk about the same thing? Entrepreneurship Theory and Practice, v. 34, n. 2, p. 289-316, 2010.

ACHTENHAGEN, L.; BRUNNINGE, O.; MELIN, L. Patterns of dynamic growth in medium-sized companies: Beyond the dichotomy of organic versus acquired growth. Long Range Planning, v. 50, n. 4, p. 457-471, 2017.

ANTONCIC, J. A.; ANTONCIC, B.; LI, Z. Creativity of the Entrepreneur, Intrapreneurship, and the Growth of Small and Medium-Sized Enterprises: Evidence from China. Chinese Business Review, v. 17, p. 336-341, 2018. doi: 10.17265/1537-1506/2018.07.003

ARROYO, M. R.; FUENTES, M. M.; JIMÉNEZ, J. M. R. An international study of the factors explaining high-growth expectation in new ventures: A gender perspective. Review of Business Management, v. 18, n. 60, p. 171190, 2016.

BARDIN, L. Análise de conteúdo. São Paulo: Edições 70, 2011.

BAUER, M. W.; GASKELL, G. Pesquisa qualitativa com texto, imagem e som: um manual prático. Petrópolis: Vozes, 2002.

BARRINGER, B. R.; JONES, F. F.; NEUBAUM, D. O. A quantitative content analysis of the characteristics of rapid growth firms and theirs founder. Journal of Business Venturing, v. 20, n. 5, p. 663-687, 2005.

BARON, R.; SHANE, S. Emprendedorismo: uma visão do processo. São Paulo: Thompson, 2005.

BULLANOVA, O.; ISAKSEN, E. J.; KOLVEREID, J. Growth aspirations among women entrepreneurs in high growth firms. Baltic Journal of Management, v. 11, n. 2, p. 187-206, 2016.

BRUSH, C. G.; CERU, D. J.; BLACKBURN, R. Pathways to entrepreneurial growth: The influence of management, marketing, and money. Business Horizons, v. 52, n. 5, p. 481-491, 2009.

CAMARGO, B. V.; JUSTO, A. M. IraMuteq: Um software gratuito para análise de dados textuais. Temas em Psicologia, v. 21, n. 2, p. 513-518, 2013.

CANO, J. A.; BAENA, J. J. Impacto de las tecnologías de información y comunicación en el desempeño de la negociación internacional. Revista Brasileira de Gestão de Negócios, v. 17, n. 54, p. 751-768, 2015.

CEGARRA-NAVARRO, J.G.; PAPA, A.; GARCIA-PEREZ, A.; FIANO, F. An open-minded strategy towards ecoinnovation: A key to sustainable growth in a global enterprise. Technological Forecasting and Social Change, v. 148, 2019. https://doi.org/10.1016/j.techfore.2019.119727

CHANDLER, G. N.; MCKELVIE, A.; DAVIDSSON, P. Asset specificity and behavioural uncertainty as moderators of the sales growth: Employment growth relationships in emerging ventures. Journal of Business Venturing, v. 24, n. 4, p. 373-387, 2009.

CIRILLO, A.; HUYBRECHTS, J.; MUSSOLINO, D.; SCIASCIA, S.; VOORDECKERS, W. Researching Family BusinesS Growth. European Management Review, v. 17, n. 3, p. 733-746, 2020. https://doi.org/10.1111/emre.12389. 
CLARKE, J.; HOLT, R.; BLUNDEL, R. Re-imagining the growth process (co)-evolving metaphorical representations of entrepreneurial growth. Entrepreneurship \& Regional Development: International Journal, v. 26, n. 34, p. 234-256, 2014.

COAD, A.; TAMVADA, J. P. Firm growth and barriers to growth among small firms in India. Small Business Economics, v. 39, n. 2, p. 383-400, 2012.

COAD, A.; FRANKISH, J.; ROBERTS, R.G.; STOREY, D. Growth paths and survival chances: An application of Gambler's Ruin theory. Journal of Business Venturing, v. 28, n. 5, p. 615-632, 2013.

DAVIDSSON, P.; ACHTENHAGEN L.; NALDI, L. Small firm growth. Foundations and Trends ${ }^{\circledR}$ in Entrepreneurship, v. 6, n. 2, p. 69-166, 2010.

DEGLIGIANNI, I.; VOUDOURIS, I.; LIOUKAS, S. Growth paths of small technology firms: The effects of different knowledge types over time. Journal of World Business, v. 50, n. 3, p. 491-504, 2015.

DELMAR, F.; WIKLUND, J. The effect of small business managers growth motivation on firm growth: A longitudinal study. Entrepreneurship Theory and Practice, v. 32, n. 3, p. 437-457, 2008.

DOBBS, M.; HAMILTON, R. T. Small business growth: Recent evidence and new directions. International Journal of Entrepreneurial Behaviour and Research, v. 13, n. 5, p. 296-322, 2007.

DOUGLAS, E. Reconstructing entrepreneurial intentions to identify predisposition for growth. Journal of Business Venturing, v. 28, n. 5, p. 633-651, 2013.

DI PETTA, A.; GOUVEIA, L. O.; BOZZO, A. L.; GONÇALVES, M. N. A Teoria do Crescimento da firma e seus 60 anos: De onde viemos e para onde vamos. Revista Ibero-Americana de Estratégia, v. 17, n. 3, p. 173-187, 2018.

FERREIRA, J. C.; PATINO, C. M. O que realmente significa o valor-p? Jornal Brasileiro de Pneumologia, v. 41, n. 5, p. 485-485, 2015.

HERMANS, J.; VANDERSTRAETEN, J.; DEJARDIN, M.; RAMDANI, D.; STAM, E.; WITTELOOSTUIJN, A. V. Ambitious entrepreneurship: Antecedents and Consequences. Working Paper. Antwerp, Belgium: University of Antwerp, 2012.

JANSSEN, F. The conceptualization of growth: Are employment and turnover interchangeable criteria? Journal of Entrepreneurship, v. 18, n. 1, p. 21-45, 2009.

KIRKWOOD, J. J. To grow or not? Growing small service firms. Journal of Small Business and Enterprise Development, v. 16, n. 3, p. 485-503, 2009.

KIRKWOOD, J. J. How women and men business owners perceive success. International Journal of Entrepreneurial Behaviour \& Research, v. 22, n. 5, p. 594-615, 2016.

LEITCH, C.; HILL, F.; NEERGAARD, H. Entrepreneurial and business growth and the quest for a "comprehensive theory": Tilting at windmills? Entrepreneurship Theory and Practice, v. 34, n. 2, p. 249-260, 2010.

LENZIARDI, R. A gestão sustentável de pequenas empresas hoteleiras em Paraty, RJ: percepções e práticas. Revista Eletrônica Gestão \& Sociedade, n. 11, 28, p. 1558-1582, 2017. doi: 10. 21171/ges. v11i 28.2106.

MACHADO, H. P. V. Crescimento de empresas na perspectiva de pequenos empreendedores de base tecnológica. Revista de Administração Contemporânea, v. 22, n. 6, p. 817-840, 2018.

MCKELVIE, A.; WIKLUND, J. Advancing firm growth research: A focus on growth mode instead of growth rate. Entrepreneurship Theory and Practice, v. 34, n. 2, p. 261-288, 2010. 
MIN, JAE-WOONG; KIM, YOUNGJUN; VONORTAS, NICHOLAS S., 2020. "Public technology transfer, commercialization and business growth," European Economic Review, v. 124(C), 2020. DOI: 10.1016/j.euroecorev.2020.103407.

MITCHELMORE, S.; ROWLEY, J. Growth, and planning strategies within women-led SMEs. Management Decision, v. 51, n. 1, p. 83-96, 2013.

MORRIS, M. H.; MIYASAKI, N. N.; WATTERS, C. E.; COOMBES, S. M. The dilemma of growth: Understanding venture size choices of women entrepreneurs. Journal of Small Business Management, v. 44, n. 2, p. 221 $244,2006$.

NASCIMENTO, A. R. A.; MENANDRO, P. R. M. Análise lexical e análise de conteúdo: Uma proposta de utilização conjugada. Estudos e Pesquisas em Psicologia. v. 6, n. 2, p. 72-88, 2006.

NEILL, S. The influence of managerial optimism and self-regulation on learning and business growth expectations within an emerging economic context. Asia Pacific Journal of Management, 37, p. 187-204, 2018.

ORSER, B. J.; HOGARTH-SCOTT, S.; RIDING, A. L. Performance, firm size, and management problem solving. Journal of Small Business Management, v. 38, n. 4, p. 129-146, 2000.

PARKER, S.; STOREY, D.; WITTELOOSTUIJN, J. What happens to gazelles? The importance of dynamic management strategy. Small Business Economics, v. 35, n. 2, p. 203-226, 2010.

PENROSE, E. A teoria do crescimento da firma. São Paulo: Editora Unicamp, 2006.

RAUCH, A.; RIJSKIJK, S. A. The effects of general and specific human capital on long-term growth and failure of newly founded businesses. Entrepreneurship Theory \& Practice, v. 37, n. 4, p. 923-941, 2013.

RENNEMO, O.; WIDDING, L. O.; BOGREN, M. Business growth through intentional and non-intentional processes. Journal of Small Business and Enterprise Development, v. 24, n. 2, p. 242-260, 2017.

SALVIATI, M. E. Manual do aplicativo Iramuteq (versão 0.7 Alpha 2 e R Versão 3.2.3). Planaltina, DF: Embrapa Cerrados, 2017.

SAUKKONEN, J. Entrepreneurs and growth: An option, obligation or obsession. In: MURA, L. (ed).

Enterpreneurship: development tendencies and empirical approach. [s.n.]: Mura Ladislav Editor, 2017. Ebook.

SCHOONJANS, B.; CAUWENBERGE, P. V.; BAUWHEDE, H. V. Formal business networking and SME growth. Small Business Economics, v. 41, n. 1, p. 169-181, 2013.

SUDIRMAN, IMAN. SISWANTO, JOKO; AISHA, ATYA NUR. Software entrepreneurs' competencies based on business growth. Journal of Research in Marketing \& Entrepreneurship, v, 22, n. 1, p. 111 -132, 2020.

VENUGOPAL, V. Investigating women's intention for entrepreneurial growth. International Journal of Gender and Entrepreneurship, v. 8, n. 1, p. 2-27, 2016.

VERSIANI, Â. F.; REZENDE, S. F. L; MAGALHÃES, A. T. N.; VAZ, S. L. The relationship between strategy making and organizational learning. Revista Brasileira de Gestão de Negócios, v. 20, n. 2, p. 157-177, 2018.

WIKLUND, J.; PATZELT, H.; SHEPHERD, D. A. Building an integrative model of small business growth. Small Business Economics, v. 32, n. 4, p. 351-374, 2009.

WRIGHT, M.; STIGLIANI, I. Entrepreneurship and growth. International Small Business Journal, v. 31, n. 1, p. $3-22,2012$. 
YUKSEL, E.; SIANNE, G-W.; SLADE, A. An exploration of entrepreneurs' identities and business growth.

Business Horizons, v. 63, n. 3, p. 391-401, 2020.

YUN, J. J.; ZHAO, X.; PARK, K.; SHI, L. Sustainability Condition of Open Innovation: Dynamic Growth of Alibaba from SME to Large Enterprise. Sustainability, v.12, 2020, doi:10.3390/su12114379. 